\title{
Padrões espaciais do capital criativo e do capital humano no Brasil: efeitos sobre o desenvolvimento econômico regional
}

\section{Spatial patterns of creative capital and human capital in Brazil: effects on regional economic development}

Natália Branco Stein

Doutoranda $^{1}$ em Economia do Desenvolvimento na Pontifícia Universidade Católica do Rio Grande do Sul, Brasil. nataliabrancostein@gmail.com

Willian Boschetti Adamczyk

Doutorando em Economia do Desenvolvimento na Pontifícia Universidade Católica do Rio Grande do Sul, Brasil. willianadamczyk@yahoo.com.br

Adelar Fochezatto

Doutor em Economia. Professor Titular do PPGE/PUCRS, Brasil

Pesquisador do CNPq. adelar@pucrs.br

\begin{abstract}
Resumo
O objetivo é investigar a distribuição espacial das classes criativas nas microrregiões brasileiras e sua relação com o desenvolvimento regional. Para isso, testa-se o poder explicativo da Teoria do Capital Criativo frente ao da Teoria do Capital Humano para as diferenças de renda per capita entre as microrregiões. Os resultados indicam que as microrregiões com maior PIB per capita e boa parte da população com alto índice educacional estão concentradas nas regiões da metade sul do Brasil. O I de Moran indicou que ambas as variáveis estão associadas com o nível de desenvolvimento das microrregiões, porém o capital humano apresentou resultado mais explicativo. $O$ teste de Indicadores de Associação Espacial Local (LISA) revelou a presença de clusters alto-alto para ambas as variáveis na metade sul. O modelo econométrico espacial apontou que o capital humano tem um efeito mais forte que o capital criativo sobre o desenvolvimento econômico das microrregiões brasileiras.
\end{abstract}

Palavras-chave: Capital Criativo, Capital Humano, Desenvolvimento Regional, Econometria Espacial, Economia Regional.

\begin{abstract}
This study aims at investigating the spatial distribution of creative classes in microregions of Brazil and its relationship with regional development. The explanatory power for the differences in product per capita of Creative Capital Theory in comparison to Human Capital Theory is empirically tested. The results showed that microregions with higher per capita GDP are concentrated in southern regions of the country, as the higher amount of schooled population. The Moran's I have indicated that both variables are associated with the development level of microregions; however, human capital had a more explicative result. Local Indicators of Spatial

\footnotetext{
${ }^{1}$ O presente trabalho foi realizado com apoio da Coordenação de Aperfeiçoamento de Pessoal de Nivel Superior Brasil (CAPES) - Código de Financiamento 001.
} 
Association (LISA) revealed the presence of high-high clusters, for both creative capital and human capital in the south of Brazil. The spatial econometric model showed that human capital has a more substantial effect than creative capital over the economic development of Brazilian microregions.

Keywords: Creative Capital, Human Capital, Regional Development, Spatial Econometrics, Regional Economy.

\section{INTRODUÇÃO}

A Teoria do Capital Humano surgiu em meados da década de 1950 e ganhou relevância na explicação do crescimento das regiões ao mostrar que o principal motor do desenvolvimento econômico é a qualificação dos indivíduos. Os defensores dessa teoria acreditam que o desenvolvimento econômico está associado ao nível de educação e, consequentemente, da produtividade dos trabalhadores (MINCER, 1958; BECKER, 1994).

Nesse contexto, Florida (2011) faz questionamentos à Teoria do Capital Humano ao investigar aspectos referentes à disponibilidade de talentos nas cidades americanas através da definição de classes criativas. Estas classes são compostas por ocupações que prestam a sua contribuição para a sociedade por meio do desenvolvimento de atividades criativas e inovadoras independentemente do seu grau de instrução.

Origina-se, assim, a Teoria do Capital Criativo que considera a presença de classes criativas como fundamentais para a promoção do desenvolvimento econômico das cidades e regiões. Resultados empíricos evidenciam que economias menos dinâmicas apresentam um menor percentual de classes criativas, enquanto que as mais desenvolvidas dispõem de um contingente expressivo de membros dessa classe (FLORIDA; TINAGLI, 2004; KERIMOGLU; KARAHASAN, 2014).

Compreendendo o conhecimento e a criatividade como um elemento protagonista do processo de desenvolvimento econômico (SELTZER; BENTLEY, 1999), a explicação do desenvolvimento regional decorrente da concentração de trabalhadores de classes criativas rivaliza com a explicação do desenvolvimento regional através da concentração de trabalhadores com elevado capital humano.

O presente estudo tem como objetivo investigar a distribuição espacial das classes criativas e do capital humano nas microrregiões brasileiras e avaliar a relação dessas variáveis com o desenvolvimento econômico regional. Assim, a principal questão a ser respondida nesse estudo é: qual teoria pode melhor explicar o nível de desenvolvimento econômico regional das microrregiões brasileiras? A Teoria do Capital Criativo ou a Teoria do Capital Humano? Para isso, testa-se empiricamente o poder explicativo da Teoria do Capital Criativo frente ao poder 
explicativo da Teoria do Capital Humano para as diferenças de renda per capita entre as microrregiões.

Para a apresentação da proposta divide-se o artigo em cinco seções. A primeira refere-se a esta introdução. Já a segunda, trata-se de uma revisão bibliográfica que está dividida em duas subseções: a primeira revisa os principais conteúdos que envolvem a Teoria do Capital Criativo e a segunda revisa alguns aspectos da Teoria do Capital Humano e suas respostas às classes criativas. A terceira seção exibe a metodologia, a quarta aponta os resultados que serão apresentados em três subseções com a análise exploratória, regressão espacial e discussão dos resultados. Por fim, a quinta seção faz as considerações finais.

\section{REVISÃO BIBLIOGRÁFICA}

\subsection{A Teoria do Capital Criativo}

Em seu livro de 2003, “A Ascensão da Classe Criativa”, Richard Florida definiu a existência de classes criativas, ou seja, classes que prestam a sua contribuição para a sociedade por meio do desenvolvimento de atividades criativas e inovadoras, independentemente do seu grau de instrução. Essa definição trabalha aspectos referentes à disponibilidade de talentos nas cidades norte-americanas, enfatizando que quanto maior for a presença de classes criativas em uma região, maiores serão suas chances de prosperar economicamente (FLORIDA, 2011).

Assim, Florida (2011) desenvolveu a Teoria do Capital Criativo ao defender que o desenvolvimento regional não se dá apenas pelas externalidades promovidas pelas aglomerações produtivas e disponibilidade de recursos, mas pela disponibilidade de pessoas talentosas. Ou seja, o autor acredita que a presença de talentos e a sua concentração regional podem potencializar a atração de atividades, firmas inovadoras, e consequentemente o desenvolvimento econômico.

O termo "criatividade" pode ser entendido como o talento para criação, inovação ou engenhosidade para inventar novas formas. Não há um consenso na literatura sobre seu conceito objetivo. Porém, é importante salientar a criatividade é reconhecida como uma habilidade fundamental e intrínseca ao ser humano, uma vez que todos trabalhadores podem ser potencialmente criativos (FLORIDA, 2003; 2011).

Deste modo, o autor definiu dois grupos profissionais. O primeiro denominou de "Classe hipercriativa", enquanto o segundo é conhecido como a "Classe dos profissionais criativos". A Classe hipercriativa é formada por engenheiros, cientistas, arquitetos, professores universitários, designers, atores, animadores, assim como lideranças de pensamento da sociedade moderna, como editores, pesquisadores, escritores, entre outros. São profissões fundamentais para o estímulo às atividades inovadoras, uma vez que este grupo é responsável por produzir novas formas de pensar, 
novas estratégias organizacionais e também novos produtos que podem ser amplamente transferidos e difundidos na sociedade (FLORIDA, 2003; 2011).

Já a Classe dos profissionais criativos é composta por uma ampla variedade de profissionais que desempenham atividades baseadas no conhecimento, tais como áreas de gestão de negócios, serviços financeiros, área da saúde e dos setores de alta tecnologia, entre outros. Segundo Florida (2003; 2011), essa classe se dedica a pensar alternativas e soluções a problemas diários, podendo ser responsável por trazer novos métodos e novas abordagens de trabalho.

O processo migratório é visto como relevante para o desenvolvimento regional, em que regiões que conseguem atrair trabalhadores da classe criativa passam a ser conhecidas como centros criativos. Os centros criativos tendem a ser regiões com mais atrativos culturais, ambientais, turísticos e econômicos. Assim, destaca-se que os centros criativos não estão ganhando força por motivos puramente econômicos, como por exemplo, a existência de recursos naturais e salários mais elevados, mas pelo desejo das classes criativas de viver nesses locais. Tais desejos são motivados por um conjunto de amenidades, como parques, praias, espaços recreativos, apresentações artísticas, museus, e demais atrativos turísticos ou culturais que satisfazem a comunidade criativa.

As empresas tendem a seguir esses profissionais ou, muitas vezes são desenvolvidas por eles. A classe criativa passa a ser atraída pelos centros criativos, pois eles contam com um ecossistema que integra todas as formas de criatividade, seja artística, cultural, tecnológica e econômica que podem se desenvolver de forma sustentável (FLORIDA, 2003; 2011).

Nesse sentido, a Teoria do Capital Criativo mostra que o desenvolvimento econômico se relaciona aos 3Ts - Tecnologia, Talento e Tolerância. Percebida como elemento central dos 3Ts, a tecnologia é vista como a principal força que motiva o crescimento econômico, sendo função tanto da inovação quanto de concentrações de empresas de alta tecnologia em uma região.

O segundo elemento central é o talento, que é dado pelo grau de qualificação da população, bem como a sua capacidade criativa. Os indivíduos talentosos aplicam a criatividade no desenvolvimento de ideias inovadoras. Ao serem compartilhadas entre as diferentes classes profissionais essas ideias geram cada vez mais valor ao processo produtivo, resultando em externalidades positivas tanto internas, quanto externas à firma, como elementos subjacentes para atingir o sucesso econômico em uma região (FLORIDA, 2002; 2003; 2011).

A tolerância é o terceiro $\mathrm{T}$ e caracteriza-se pela capacidade de uma região absorver indivíduos com elevado grau de abertura à diversidade: étnica, religiosa, racial e população LGBT (lésbicas, gays, bissexuais, travestis e transexuais). Assim, o grau de tolerância das cidades e regiões afeta a capacidade de mobilizar a criatividade local. Portanto, quanto mais tolerante e aberta for uma região, maior será sua população criativa (FLORIDA, 2003; 2011). 
Para que a classe criativa possa produzir resultados positivos e de grande impacto ao desenvolvimento econômico, a atmosfera do local não deve reprimir a sua forma de ser, pensar e de se expressar (FLORIDA, 2002; 2011). Segundo Florida e Gates (2003), as regiões mais tolerantes são, portanto, capazes de atrair um grande conjunto de talentos de diferentes nacionalidades, obtendo vantagens competitivas, o que as torna aptas a gerar e atrair atividades produtivas com alto nível tecnológico. Além disso, a interação entre profissionais de diferentes origens e com grau de instrução elevado tende a produzir um ambiente muito mais eficiente e estimulante, podendo culminar em desenvolvimento de projetos cada vez mais inovadores, contribuindo para os processos de desenvolvimento econômico.

Entende-se, portanto, que a classe criativa é composta por indivíduos talentosos e tolerantes, cuja ação resulta na criação de novas tecnologias e inovações, constituindo um ciclo próspero de desenvolvimento econômico (FLORIDA; TINAGLI, 2004).

\subsection{A Teoria do Capital Humano e as críticas ao Capital Criativo}

Os estudos a respeito dos fatores determinantes do crescimento econômico das regiões atribuem papel de destaque ao capital humano (MANKIW; ROMER; WEIL, 1992), além do capital físico e recursos naturais. A variável de capital humano é caracterizada por Becker (1994) pelas capacidades e habilidades produtivas que o indivíduo pode adquirir devido aos investimentos individuais realizados em educação que podem gerar valor aos processos produtivos.

Teóricos do capital humano destacam que a concentração de indivíduos educados pode produzir resultados positivos à economia, uma vez que os indivíduos que adquirem mais educação recebem uma taxa de retorno mais alta por meio de seus salários. Além disso, maior nível de conhecimento impacta diretamente na produtividade do trabalhador e, consequentemente, nos lucros dos capitalistas, beneficiando o processo de crescimento e desenvolvimento econômico (LUCAS, 1988; BECKER, 1994). A importância do capital humano tem sido exaustivamente documentada na literatura econômica (SIMON; NARDINELLI 2002; FAGGIN; McCANN, 2009), mas não está isenta de questionamentos (SEN, 2000).

Assim, as reflexões introduzidas pela Teoria do Capital Criativo por Florida (2003) suscitaram debates e respostas críticas dos defensores da Teoria do Capital Humano. Dentre eles, Glaeser (2005) valoriza o fato de Florida ter analisado em conjunto a importância de distintas ocupações criativas como engenharia, arquitetura, profissionais das finanças e artistas. Porém, o autor mostra que a escolaridade (qualificação profissional), passa a eliminar a influência do núcleo criativo quando inserida em regressões de diferenças regionais. Assim, a explicação das classes criativas torna-se estatisticamente insignificante quando comparada à Teoria do Capital Humano. 
Desta forma, Glaeser (2005) considera que a chave do desenvolvimento urbano e regional não está na existência do capital criativo, e sim na presença do capital humano, pois ele supera as variáveis de capital criativo na previsão do crescimento e desenvolvimento econômico. Hoyman e Faricy (2009) também mostram que a classe criativa falha em explicar o crescimento do emprego, o crescimento dos salários ou os níveis absolutos de salários, em comparação com o capital humano. Assim, a conclusão desses autores é contrária aos preceitos de Florida, uma vez que estes verificaram que a Teoria do Capital Humano supera a Teoria do Capital Criativo na previsão do sucesso econômico.

Kerimoglu e Karahasan (2014) tentaram, por meio de econometria espacial, identificar o impacto da presença das classes criativas nas regiões da Espanha. Os resultados indicaram que a variável de capital humano consegue explicar com mais propriedade a sua relação de dependência com o desenvolvimento econômico. Neste trabalho, o capital criativo consegue explicar de alguma maneira o desenvolvimento nas regiões da Espanha, porém quando eles incorporaram a variável de capital humano no modelo, o resultado da regressão supera o apresentado pelo capital criativo. Assim, os resultados apontados por esses autores seguem rumos contrários ao que Florida verifica.

A crítica de Markusen (2006) baseia-se principalmente na relação de causalidade entre a noção de classe criativa e a relação com desenvolvimento econômico. Para o autor a formação, localização e o impacto urbano das ocupações criativas se dão de forma mais complexa do que foi apontado por Florida. O autor critica a comparação entre as classes de artistas, por exemplo, com profissionais da área do direito, pois esses profissionais possuem motivações diferentes, que podem os levar a optar por locais distintos para viver. Além disso, mostrar que o crescimento e a alta tecnologia são funções da presença de classes criativas captura, na visão do autor, apenas o alto capital humano medido pela sua qualificação e não outras habilidades.

Realizando uma crítica direta a análise de Florida, Vivant (2006) defende que o fluxo de talentos não é causa, mas uma consequência do crescimento econômico. A autora questiona também os critérios de decisão de localização residencial dos indivíduos, que está mais ligada a oferta de bons empregos e instituições de ensino do que propriamente atividades culturais ou amenidades. Ela afirma, que ao defender essa ideia, Florida toma como base a sua experiência e motivação pessoal, esquecendo-se das necessidades da população menos favorecida economicamente.

Além dos fatores mencionados, é de se reconhecer que a definição de classes criativas pode não se adequar a realidades distintas das metrópoles de sociedades democráticas, livres e progressistas consideradas por Florida (2011). Sociedades em que o pensamento conservador ou autoritário predomina podem ter em suas classes criativas o papel de reprodução de paradigmas estáticos ou acríticos em relação ao status quo. 
A criatividade, conforme Landry (2013) pode ser restrita pelos diferentes contextos institucionais em que está inserida. Assim, podem existir dificuldades na compatibilização do que se considera como ocupações criativas entre os países, uma vez que as semelhanças entre as funções desempenhadas pelos profissionais em diferentes realidades nem sempre retratam o seu grau de criatividade.

\section{METODOLOGIA}

Os critérios de seleção das classes criativas analisadas nesta pesquisa baseiam-se na triagem realizada por Florida (2011). O autor divide as classes criativas em dois subcomponentes principais: centro hipercriativo ${ }^{2}$ e profissionais criativos ${ }^{3}$. A partir desta divisão o autor decompôs sua lista de profissões utilizando como fonte de dados a Occupational Employment Survey (OES), pesquisa promovida pelo Bureau of Labor Statistic (BLS) dos Estados Unidos.

Para a realização deste artigo, analisa-se a divisão de subcomponentes, bem como a lista de ocupações da OES e realiza-se a seleção de 128 ocupações junto a Classificação Brasileira de Ocupações (CBO) que, de acordo com os mesmos critérios, são consideradas criativas. Assim, as classes criativas selecionadas nessa pesquisa são extraídas da CBO 2002 Família com os dados de trabalhadores da Relação Anual de Informações Sociais (RAIS) do ano de 2016.

A observação da variável capital humano dá-se pelo índice educacional dos municípios, fornecida pela FIRJAN. Essa variável refere-se ao ano de 2016 e é tratada nesse artigo como proxy de capital humano. Quanto a variável que representa o desenvolvimento econômico, utiliza-se os dados de PIB per capita, extraídos junto ao IBGE referentes a 2015, ano mais recente disponibilizado pela instituição.

Ainda que se reconheça as diferenças entre os conceitos de desenvolvimento e crescimento econômico ressaltadas na literatura de desenvolvimento humano (SEN, 2000) a escolha do PIB per capita como proxy de desenvolvimento parte do entendimento de Florida $(2002,2011,2012)$ a respeito desses conceitos. Em seus trabalhos, assim como dos autores que o sucederam, a exemplo de Kerimoglu e Karahasan (2014) e Mellander e Florida (2006) foram utilizadas variáveis de renda como proxy de desenvolvimento. Essas variáveis são entendidas nas literaturas de desenvolvimento humano como medidas de crescimento e não como de desenvolvimento econômico, visto que na visão dessa corrente de pensamento captam apenas dimensões quantitativas, não considerando elementos subjetivos e qualitativos na vida da sociedade. No entanto, Florida e demais autores citados entendem o desenvolvimento econômico regional como o nível de vida geral de uma região,

\footnotetext{
2 Profissões ligadas à computação e a matemática, agricultura, engenharias, ciências biológicas, naturais e sociais, educação, treinamento, biblioteconomia, artes, design, entretenimento, esportes e mídias.

${ }^{3}$ Profissões gerenciais, ligadas aos negócios, às operações financeiras, ao direito, à área da saúde e ao gerenciamento de vendas de alto nível (FLORIDA, 2011, p. 328).
} 
aspecto que pode ser mensurado pelo PIB per capita, uma variável de renda. Assim, o uso desse dado parte do entendimento de que o crescimento mensurado pelo PIB per capita é, portanto, uma condição necessária ao desenvolvimento.

Opta-se por trabalhar com 558 microrregiões devido a maior estabilidade espacial das observações dado que níveis maiores de desagregação sofrem de alterações nas unidades espaciais ao longo do tempo, gerando informações menos confiáveis ou ausentes. Além disso, considera-se sem prejuízos que indivíduos da classe criativa se deslocam para trabalhar dentro da mesma microrregião, ao residir em um local e trabalhar em município vizinho.

Em posse dos dados apresentados, realiza-se a análise da distribuição espacial do PIB per capita, do capital humano e do capital criativo por meio da observação dos dados e representações cartográficas. Logo, inicia-se a análise exploratória de dados espaciais a fim de entender de que maneira o capital criativo e capital humano estão associados ao desenvolvimento econômico presente nas microrregiões brasileiras através das técnicas de autocorrelação espacial.

O coeficiente de autocorrelação espacial I de Moran pode ser utilizado para apontar se alguma variável é dependente de sua localização geográfica. Ou seja, a estatística mostra se a variável analisada segue ou não um padrão espacial aleatório. (FOCHEZATTO; TARTARUGA, 2015; ALMEIDA, 2012). Salienta-se que através do I de Moran global é possível observar a existência de correlação espacial. A hipótese nula é de aleatoriedade na distribuição espacial dos dados. Assim, o nível de significância para rejeição da hipótese nula informa se os dados não estão distribuídos de forma aleatória. Quanto à magnitude da estatística, mostra a força da autocorrelação espacial. Os resultados mais próximos de 1 ou -1, indicam uma concentração mais forte, enquanto que aqueles mais próximos de 0 , indicam uma maior dispersão dos dados (ALMEIDA, 2012).

A fim de complementar as informações de autocorrelação espacial global dadas pelo I de Moran investiga-se a existência de autocorrelação local através dos Indicadores de Associação Espacial Local (LISA - Local Indicators of Spatial Association) (ANSELIN, 1999; ALMEIDA, 2012). Assim, considera-se a hipótese de ocorrer autocorrelação espacial entre algumas microrregiões brasileiras e não em outras, apontando a formação de clusters espaciais.

As diferenças regionais no Brasil são observadas pela renda per capita de suas microrregiões, ou seja, a variável PIB per capita é considerada como proxy ao desenvolvimento econômico. Desta maneira, a segunda parte da análise pretende entender qual variável (de capital criativo ou de capital humano), possui maior poder explicativo para as diferenças de renda per capita entre as microrregiões brasileiras, ou seja, qual variável possui maior relação com o desenvolvimento econômico regional. Essa relação é modelada por:

$$
y=f(C K, H K)
$$


Inspirada no trabalho de Kerimoglu e Karahasan (2014) a equação apresentada representa a hipótese investigada neste trabalho, de que o capital criativo $(C K)$ ou o capital humano $(H K)$ estão afetando as diferenças regionais de renda per capita (y). Em comparação ao modelo de Kerimoglu e Karahasan (2014), uma limitação do trabalho é a ausência de dados representativos do capital físico das microrregiões brasileiras em anos recentes. Desse modo, é estimada a relação de dependência entre a variável PIB per capita e a participação do capital criativo e posteriormente entre o PIB per capita e a variável capital humano para entender se a correlação está presente no resíduo ou na variável.

A realização de análises espaciais depende da especificação da matriz de contiguidade. Assim, a Tabela 1 apresenta o teste da dependência espacial do PIB per capita das microrregiões através do I de Moran considerando matrizes de contiguidade Queen, Rook e K-Nearest Neighbors ( $\mathrm{KNN})$, com 1, 3 e 5 vizinhos mais próximos.

Segundo Baumont (2004), a estratégia mais apropriada é calcular as diferentes ordens de matrizes do I de Moran univariado. Aquela que apresentar o resultado com maior valor deverá ser utilizada nos modelos. A matriz Rook de ordem 1 é escolhida por apresentar o maior coeficiente do I de Moran, 0,756. A indicação da matriz Rook também foi obtida ao analisar as demais variáveis de capital criativo e capital humano.

Tabela 1: I de Moran Univariado para o PIB per capita das microrregiões brasileiras.

\begin{tabular}{cccc}
\hline Matrizes & Queen & Rook & KNN \\
\hline Ordem 1 & 0,755 & $\mathbf{0 , 7 5 6}$ & 0,742 \\
Ordem 3 & 0,633 & 0,633 & 0,747 \\
Ordem 5 & 0,570 & 0,572 & 0,746 \\
\hline
\end{tabular}

Fonte: Elaboração própria.

A fim de diagnosticar o caráter da dependência espacial e, portanto, o melhor modelo a ser utilizado, são conduzidos testes de Multiplicador de Lagrange (LM) simples e robusto para a dependência espacial do PIB per capita e dos resíduos da regressão. Os métodos são aplicados com o uso do software GeoDa 1.6.

\section{RESULTADOS}

\subsection{Análise Exploratória}

A fim de identificar a distribuição e localização do capital criativo e do capital humano no Brasil, bem como a sua associação com o nível de desenvolvimento econômico, verificou-se inicialmente a distribuição geográfica do PIB per capita, do índice de educação e dos trabalhadores criativos nas microrregiões brasileiras apresentados na Figura 1. 
Na Figura 1-a é possível observar que as microrregiões brasileiras com maior PIB per capita estão localizadas nas regiões Centro-Oeste, Sudeste e Sul do país, indicando um maior grau de desenvolvimento ao considerar a renda média por cada habitante da microrregião. É estatisticamente significativa a evidência de autocorrelação espacial no comportamento do PIB per capita, já que seu I de Moran foi calculado em 0,756. Essa correlação positiva indica que microrregiões com elevada renda tendem a estar próximas a regiões de elevada renda, enquanto microrregiões com menor grau de desenvolvimento tendem a estar cercadas por semelhantes.

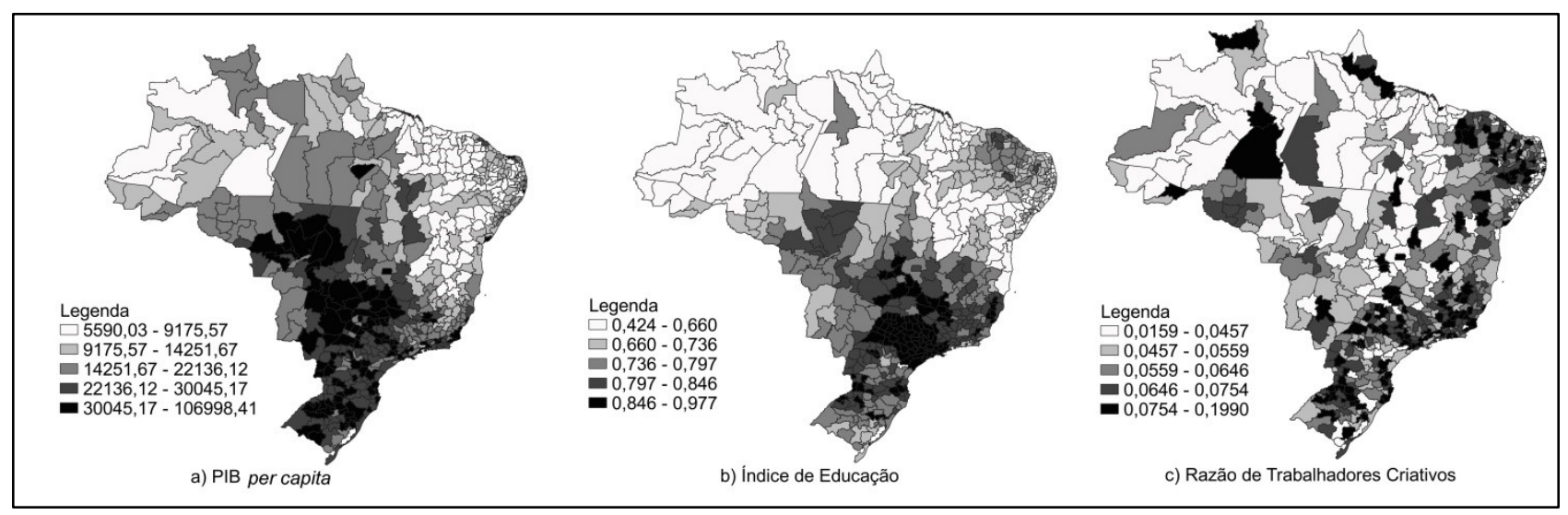

Figura 1 - Distribuição geográfica do PIB per capita, do índice de educação e dos trabalhadores criativos nas microrregiões do Brasil.

Fonte: Elaboração própria.

Na Figura 1-b observa-se a distribuição espacial média do capital humano, aqui representado pelo Índice de Educação oriundo do Índice FIRJAN de Desenvolvimento Municipal, nas microrregiões brasileiras. $\mathrm{O}$ índice varia entre 0 e 1 , sendo que quanto maior, mais elevado o nível educacional. Os maiores índices verificados são das microrregiões de localizadas no estado de São Paulo, indicando a concentração de altos índices educacionais nas regiões Sudeste, Sul e Centro-Oeste.

Os mais baixos índices de educação concentram-se nas microrregiões localizadas ao Norte e à Nordeste do país. Em meio a região Nordeste destaca-se um cluster com altos índices educacionais, nas localidades de Brejo Santo - CE (0,842), Seridó Oriental - RN $(0,838)$, Baixo Curu - CE (0,835), Meruoca - CE (0,832), Santa Quitéria - CE (0,822). A presença das microrregiões do Ceará (CE) pode ser efeito de reconhecidas políticas educacionais implementadas no estado, como o programa Prêmio Escola Nota 10, pertencente ao Sistema Permanente de Avaliação de Educação Básica do Ceará (SPAECE), que vem apresentando efeitos positivos no desempenho de alunos do Ensino Fundamental (CARNEIRO, 2015). As causas para demais localidades destoarem do restante da região Nordeste e Norte merecem uma investigação futura. 
Uma evidência adicional da dependência espacial do capital humano é oferecida através da análise de seu I de Moran. O coeficiente de 0,864 é significativo e considerado forte. Assim, podese afirmar que há uma correlação espacial positiva entre os índices educacionais nas microrregiões. Em locais que se verifica alto índice, é mais provável que os vizinhos também possuem alto índice educacional, enquanto microrregiões com resultados inferiores estão ligados a regiões com baixos índices educacionais.

Na Figura 1-c encontra-se a razão de trabalhadores criativos no total de trabalhadores da microrregião. Assim, a participação de trabalhadores pertencentes ao grupo de criativos é também mais significativa em microrregiões localizadas na região Sul, Sudeste e Centro-Oeste, com destaque para algumas microrregiões do Nordeste que também revelaram participações elevadas de profissionais criativos. Os resultados mostram que entre as 15 microrregiões com maior participação de trabalhadores criativos, destacam-se cinco microrregiões localizadas apenas no estado de São Paulo ${ }^{4}$ evidenciando a alta concentração dessa população na região Sudeste. Nesta análise, também chamou a atenção a participação dos trabalhadores criativos da microrregião Santa Quitéria (19\%) no Ceará, e Serrana do Sertão Alagoano (12\%) localizada no estado do Alagoas, ambas pertencentes à região Nordeste do Brasil.

A dependência espacial da razão de trabalhadores criativos pode ser conferida na análise do I de Moran, o qual evidenciou um coeficiente de 0,277 Esse resultado revela que onde é verificada maior razão de trabalhadores criativos é mais provável que os vizinhos também possuam alta razão de trabalhadores criativos, enquanto microrregiões com resultados inferiores estão ligados a regiões com baixa participação de criativos. Embora esse coeficiente seja significativo e indique uma relação positiva entre a razão de trabalhadores criativos nas microrregiões, seu resultado está mais distante da unidade do que o I de Moran do índice educacional, sugerindo que sua concentração de vizinhos semelhantes é mais fraca do que as observadas na análise do índice educacional.

A partir disto, na Figura 2 é possível conferir o Índice de Autocorrelação Espacial Global Bivariado que representa a relação existente entre o PIB per capita e a razão de trabalhadores criativos, assim como entre o PIB per capita e o Índice de educação.

Conforme aponta a Figura 2-a, o índice de Autocorrelação Espacial Global Bivariado é de 0,137, indicando a existência de relação positiva entre a variável PIB per capita e a razão de trabalhadores criativos. Esse resultado indica fracamente que locais com alto PIB per capita estão cercados por microrregiões de alto capital criativo, assim como localidades com baixo PIB per capita são pouco rodeadas por microrregiões com baixa participação do capital criativo.

\footnotetext{
${ }^{4}$ Osasco (14\%), São Paulo (13\%), Franca (11\%), Campinas e São José do Rio Preto (10\%). 
Assim como no caso anterior, observa-se através da Figura 2-b a existência de dependência espacial positiva entre as variáveis PIB per capita e o índice de educação. Ou seja, identifica-se a existência de uma relação direta e positiva entre o PIB per capita e a variável de educação, o que significa dizer que à medida em que o capital humano aumenta (diminui), o PIB per capita também aumenta (diminui). Isso indica que locais com alto PIB per capita estão cercados por microrregiões de alto capital humano, assim como locais com baixo PIB per capita estão cercados por microrregiões de baixo capital humano.

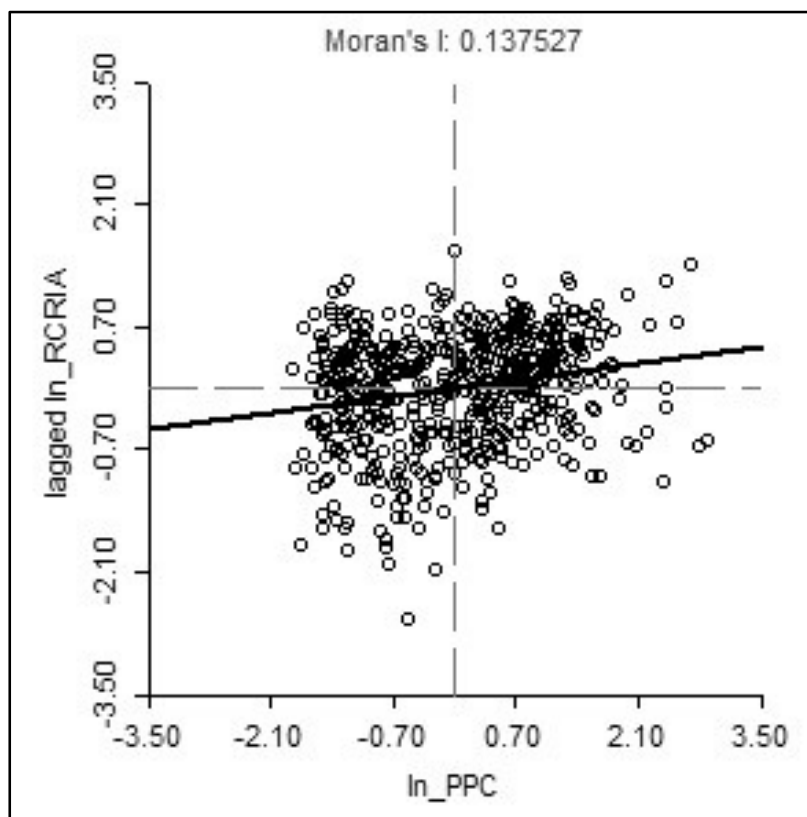

(a) PIB per capita e Razão dos Trabalhadores Criativos

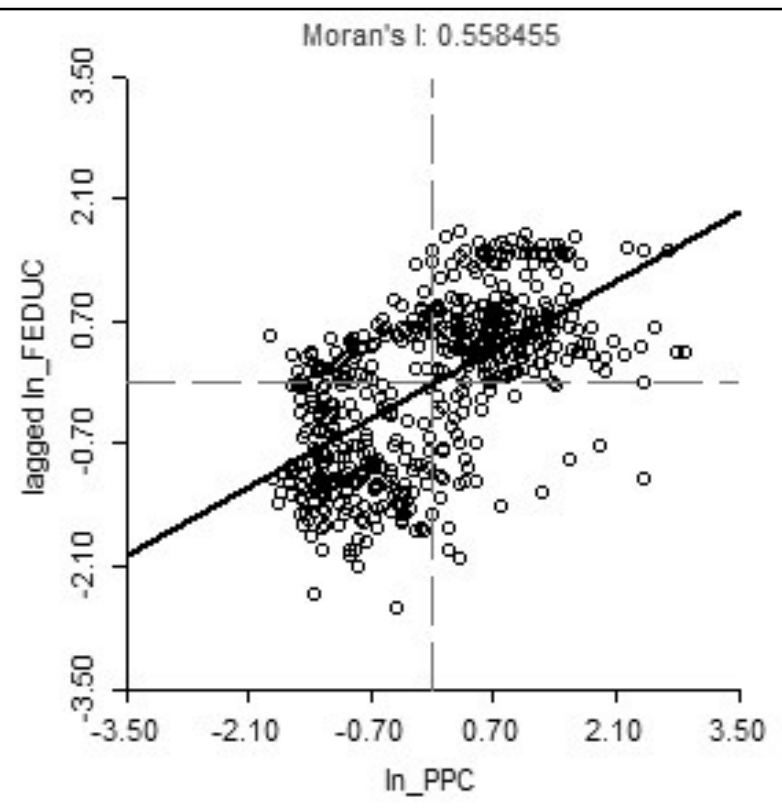

(b) PIB per capita e Índice de Educação

Figura 2 - I de Moran Bivariado para as variáveis selecionadas.

Fonte: Elaboração própria.

No entanto, o coeficiente de 0,558 , revela que a relação de dependência entre PIB per capita e índice de educação é mais forte do que a obtida entre as variáveis PIB per capita e razão dos trabalhadores criativos. Embora a variável de capital criativo esteja associada ao desenvolvimento econômico presente nas microrregiões, o resultado do I de Moran mais próximo da unidade evidenciado em 2-b propõe que o capital humano possui maior associação com o desenvolvimento econômico regional do que a variável capital criativo.

A fim de complementar a análise, a Figura 3 traz a visualização cartográfica dos padrões de associação espacial dados pelos Indicadores de Associação Espacial Local (LISA). Na figura 3-a nota-se a existência de dois clusters relevantes para a relação PIB per capita e a razão de trabalhadores criativos. O primeiro compreende microrregiões localizadas na região Sul e Sudeste do país, ou seja, áreas com melhores níveis de desenvolvimento. Revelam-se clusters do tipo AltoAlto (High-High), ou seja, de aglomerações de microrregiões que possuem alto PIB per capita e 
que estão cercadas por aquelas que possuem alta participação do capital criativo. O segundo agrupamento envolve microrregiões localizadas na região Norte e Nordeste do país, ou seja, em áreas conhecidas pelo seu baixo grau de desenvolvimento econômico. Sendo assim, evidencia-se a existência de um cluster Baixo-Baixo (Low-Low), que representa aglomerações de microrregiões com baixo PIB per capita cercadas daquelas que possuem baixo capital criativo.

A existência de clusters que evidenciam o poder de associação entre o capital criativo com desenvolvimento econômico reforçam os argumentos trazidos pela Teoria do Capital Criativo, que defende que regiões com maior concentração de profissionais criativos tendem a ser mais desenvolvidas.

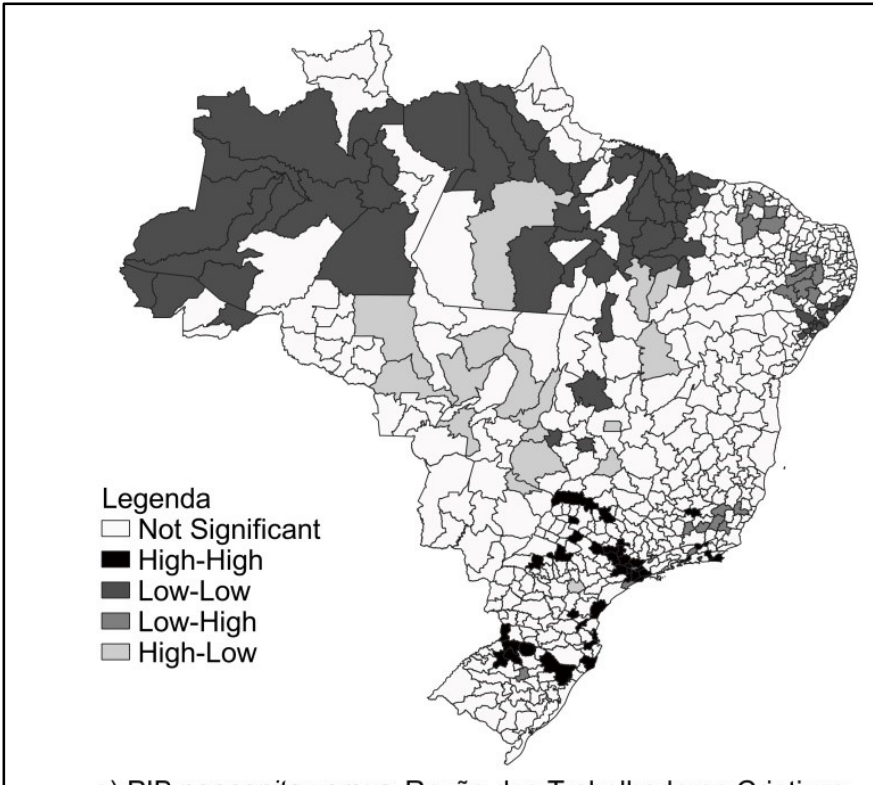

a) PIB per capita versus Razão dos Trabalhadores Criativos

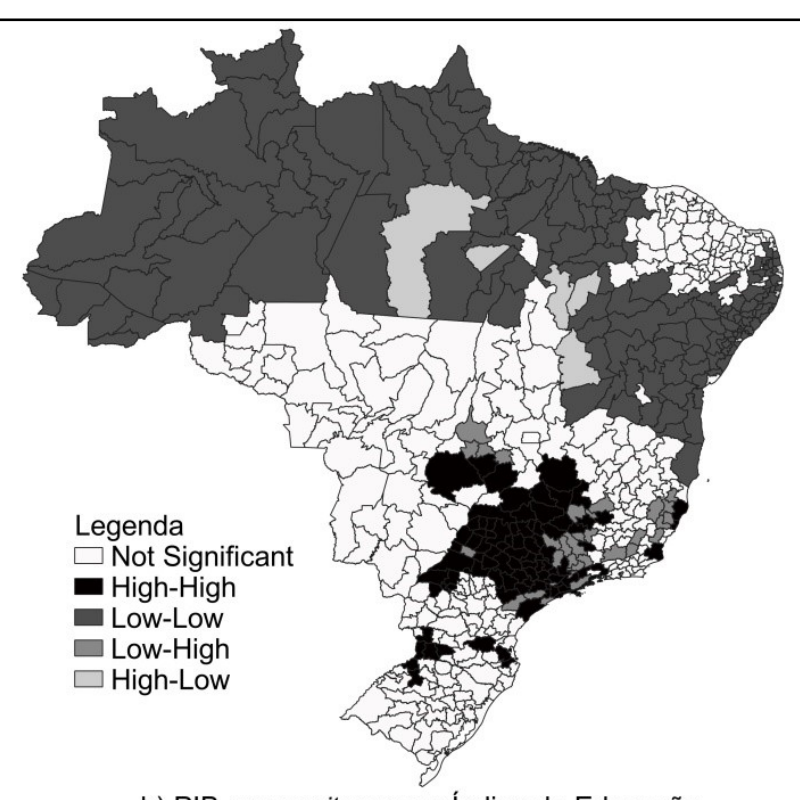

b) PIB per capita versus Índice de Educação

Figura 3 - Índice de Autocorrelação Espacial Local para as variáveis selecionadas. Fonte: Elaboração própria.

Na figura 3-b verifica-se a existência de dois clusters relevantes, porém agora entre o PIB per capita e a variável índice de educação. O primeiro, também localizado na região Sul e Sudeste formam clusters do tipo Alto-Alto (High-High), ou seja, aglomerações com alto PIB per capita que estão cercadas de microrregiões com alto nível de capital humano. O segundo agrupamento compreende aglomerações localizadas ao Norte e ao Nordeste do país e evidenciam a existência de clusters Baixo-Baixo (Low-Low), ou seja, de aglomerações de microrregiões de baixo PIB per capita que estão cercadas por outras com baixo nível de capital humano.

Da mesma forma, esses resultados fortalecem os argumentos trazidos pelos teóricos do Capital Humano de que o nível de educação dos indivíduos de uma nação pode influenciar seu nível de desenvolvimento econômico. 


\subsection{Análise de Regressão Espacial}

A etapa seguinte da análise compreende a estimação de uma equação de dependência espacial entre a variáveis PIB per capita, a participação do capital criativo e a variável de capital humano. A fim de identificar a ocorrência de dependência espacial, apresenta-se a seguir os seguintes testes: o teste do I de Moran aplicado aos resíduos da estimação; o teste do Multiplicador de Lagrange robusto (ML) e o teste do Multiplicador de Lagrange (ML) para o erro. Conforme os resultados dos testes, realiza-se a escolha do modelo de econometria espacial mais adequado ao objetivo proposto.

A Tabela 2 apresenta os resultados dos testes que foram calculados para indicar qual é o melhor modelo a ser estimado para o ano de 2016. Assim, os testes apontam que o método de Mínimos Quadrados Ordinários não é mais adequado para a análise. Observando o resultado do teste I de Moran, nota-se que ele é significativo estatisticamente, pois apresenta $1 \%$ de significância. Desta forma, o resultado do I de Moran sinaliza a existência de autocorrelação espacial. Já o teste mais significativo, ML $\lambda$ (erro robusto), informa que o modelo mais apropriado ao objetivo do presente artigo é o de Spatial Error Model (SEM).

Tabela 2: Diagnóstico de dependência espacial - Matriz Rook 1.

\begin{tabular}{lcl}
\hline \multicolumn{1}{c}{ Teste } & Coeficiente & P-valor \\
\hline I de Moran & 0,60 & $0,00^{* * *}$ \\
ML $\rho$ (defasagem) & 77,82 & $0,00^{* * *}$ \\
ML $\rho$ (defasagem robusta) & 2,40 & 0,12 \\
ML $\lambda$ (erro) & 494,70 & $0,00^{* * *}$ \\
ML $\lambda$ (erro robusto) & 419,28 & $0,00^{* * *}$ \\
\hline
\end{tabular}

Fonte: Elaboração própria.

*Significativo a $10 \%, * *$ Significativo a $5 \%, * * *$ Significativo a $1 \%$.

O modelo Spatial Error Model (SEM) da tabela 3 inclui a variável participação do capital criativo e o índice de educação. O SEM considera a dependência espacial nos resíduos, ou seja, a possibilidade de haver interferências de variáveis correlacionadas espacialmente com a variável explicada ou com as variáveis explicativas e que não estão incluídas explicitamente no modelo (ALMEIDA, 2012).

Analisando as variáveis em conjunto nota-se que elas possuem a capacidade de explicar adequadamente o modelo, sendo um indicativo de que as duas variáveis estariam explicando o desenvolvimento das microrregiões brasileiras. Por ter sido estimado em $\log$-log, os resultados deste modelo indicam um aumento de $1 \%$ na razão do capital criativo gera um aumento de $0,12 \%$ no PIB per capita, enquanto que um aumento de $1 \%$ no Índice de educação gera um aumento de 1,52\% no 
PIB per capita. Todos os coeficientes são estatisticamente significativos a 1\%, exceto do capital criativo, à $5 \%$.

Tabela 3: Resultados do Modelo SEM do PIB per capita em log-log.

\begin{tabular}{lcccc}
\hline \multicolumn{1}{c}{ Variável } & Coeficiente & Desvio-padrão & Est. $\mathbf{z}$ & p-valor \\
\hline Constante & 3,08 & 1,00 & 3,08 & $0,00^{* * *}$ \\
\% Trab.Criativos & 0,12 & 0,05 & 2,54 & $0,01^{* *}$ \\
Índice de Educ. & 1,52 & 0,23 & 6,50 & $0,00^{* * *}$ \\
Lambda $(\lambda)$ & 0,80 & 0,03 & 29,00 & $0,00^{* * *}$ \\
\hline Pseudo-R & 0,74 & & & \\
Breusch-Pagan & 4,78 & & & $0,09^{*}$ \\
\hline
\end{tabular}

Fonte: Elaboração própria.

*Significativo a $10 \%,{ }^{* *}$ Significativo a $5 \%, * * *$ Significativo a $1 \%$.

O Pseudo- $\mathrm{R}^{2}$ demonstra um elevado poder explicativo do modelo $(0,74)$ enquanto o teste para heterocedasticidade de Breusch-Pagan não é significativo a 5\%. Após a estimação do modelo SEM verifica-se o desaparecimento da autocorrelação espacial nos resíduos, com um I de Moran não significativo a $5 \%$, com coeficiente $-0,05$.

Dessa forma, percebe-se que a variável de capital humano tem maior relação com o nível de desenvolvimento econômico. Essa relação aproxima-se de 13 vezes em favor do capital humano ao realizar a comparação entre o coeficiente de capital humano $(1,52)$ com o de capital criativo $(0,12)$. Esses resultados oferecem evidências em favor das críticas à Teoria do Capital Criativo, já que os defensores da Teoria do Capital Humano percebem um papel explicativo maior dos níveis educacionais. Tais resultados confirmam o maior poder explicativo do Índice de educação para o padrão de PIB per capita indicados anteriormente pelos resultados do I de Moran Bivariado e pela análise de Autocorrelação Espacial Local (LISA).

\subsection{Discussão dos resultados}

A partir dos resultados encontrados é possível refletir sobre a influência da distribuição do capital humano e do capital criativo sobre as diferenças econômicas entre as microrregiões brasileiras. A relevância da análise espacial das desigualdades regionais é corroborada pelas análises exploratórias que mostram que as regiões localizadas na metade Sul do país são as que detêm maiores proporções de capital humano e de capital criativo, e consequentemente, maiores níveis de desenvolvimento econômico regional.

Dentre as possíveis interpretações das disparidades, Lima e Lima (2016) elencam a existência de "armadilhas de pobreza" e de "causação circular cumulativa". Esses efeitos permitem 
explicar a manutenção dos padrões de desenvolvimento das regiões ao longo do tempo. Há uma tendência de que regiões mais pobres se mantenham cercadas por regiões com baixos índices de desenvolvimento, assim como regiões mais bem-sucedidas permaneçam rodeadas por regiões com melhores níveis de desenvolvimento econômico. Dessa forma, a importância do espaço para a trajetória de crescimento das economias é destacada, dado que regiões com vizinhos ricos tendem a se beneficiar, enquanto vizinhos pobres tendem a prejudicar o desenvolvimento econômico (LIMA e LIMA, 2016).

A participação de trabalhadores criativos concentra-se em microrregiões predominantemente urbanas no estado de São Paulo. Segundo o Instituto Brasileiro de Geografia e Estatística (IBGE, 2008) os municípios dessas microrregiões possuem influência local e regional compondo uma rede urbana que atrai grande contingente populacional. Por estar na região de influência direta da capital São Paulo, maior metrópole nacional, servem como referências para negócios, ensino, lazer e dinamismo cultural atraindo diversidade de pessoas. Florida (2011) ressalta tais características como determinantes para atração de profissionais criativos.

Na região Nordeste, Santa Quitéria - (CE) e Serrana do Sertão Alagoano - (AL) destacamse como duas microrregiões fora do eixo Centro-Sul com elevada participação de profissionais criativos. Essas microrregiões possuem tradição nas atividades de artesanato, turismo e também apresentam cidades com festas culturais e patrimônios históricos podendo formar, de acordo com Florida (2011) um ambiente integrado de amenidades que compõem ambientes de lazer e cultura, fornecendo subsídios às diferentes formas de criatividade.

Assim, tanto os fatores de crescimento defendidos pela Teoria do Capital Humano, quanto os da Teoria do Capital Criativo estão relacionados positivamente com o processo de crescimento econômico regional, dadas as correlações espaciais encontradas. No entanto, ao confrontar os resultados dos testes do I de Moran bivariado (global e local) nota-se que o capital humano apresentou resultados mais expressivos em todos os testes, levando ao entendimento de que essa variável tem maior poder de explicar os níveis de desenvolvimento econômico.

Os resultados obtidos pela regressão espacial revelam uma relação 13 vezes maior do capital humano com o desenvolvimento econômico em comparação ao capital criativo. Essa evidência reforça os argumentos críticos à Teoria do Capital Criativo trazidos por Glaeser (2005), Hoyman e Faricy (2009) e Kerimoglu e Karahasan (2014). Tais autores encontraram resultados semelhantes ao testarem a relação de ambas as variáveis com proxies de desenvolvimento econômico e também verificaram que a influência do capital criativo é enfraquecida ou até mesmo eliminada quando se incorpora variáveis de capital humano aos modelos.

A pouca relevância atribuída à explicação das classes criativas no Brasil pode estar relacionada a baixa representatividade dos trabalhadores criativos no país. Em sua obra, Florida 
(2012) compara a participação dos trabalhadores criativos na economia nacional de diferentes países ao redor do mundo e identificou uma participação de até $43,9 \%$ da população criativa entre as economias da OCDE.

No Brasil, este estudo considerou uma participação total de trabalhadores criativos de apenas $8,7 \%$ em relação aos trabalhadores formais. No entanto, os empregos criativos, em especial os da classe artística, são caracterizados pela elevada informalidade, o que não foi possível de capturar nesse estudo em razão da indisponibilidade de dados no nível de desagregação espacial proposto. O uso de dados administrativos, como a RAIS, traz a limitação de considerar apenas o emprego formal declarado pelas empresas.

Dessa forma, o presente estudo utiliza a definição mais abrangente de classes criativas profissionais a fim de lidar com essa limitação. Cabe ressaltar, no entanto, que o reconhecimento das raízes culturais e criativas, ou seja, o valor daquilo que é intangível e que poderia ser melhor retratado com a inclusão dos informais e atividades que não visam o ganho econômico, está cada vez mais presente nas discussões sobre estratégias de desenvolvimento econômico e merece espaço em pesquisas futuras.

\section{CONSIDERAÇÕES FINAIS}

O presente estudo visou identificar o padrão de distribuição espacial do capital criativo e do capital humano no Brasil e sua associação com as diferenças nos níveis de desenvolvimento econômico das microrregiões.

A maior participação de trabalhadores criativos no total do emprego concentra-se em microrregiões predominantemente urbanas da metade Sul do Brasil, em especial no estado de São Paulo. Essas microrregiões atraem a diversidade de pessoas ao concentrar atividades de negócios, ensino, lazer e dinamismo cultural. Da mesma forma, o capital humano, também se mostrou concentrado nas microrregiões da metade Sul, sugerindo associação entre a presença de capital criativo e capital humano com o desenvolvimento econômico, dado que essa região do país é conhecida pela representatividade econômica.

Essa associação foi evidenciada nos testes I de Moran, cujos resultados positivos evidenciam que locais com maior razão de trabalhadores criativos possuem vizinhos com alta razão de trabalhadores criativos, enquanto microrregiões com resultados inferiores estão ligados a regiões com baixa participação de criativos. Verificou-se também a correlação espacial positiva entre os índices educacionais nas microrregiões. Em locais em que se verifica alto índice, os vizinhos também possuem alto índice educacional, enquanto microrregiões com resultados inferiores estão 
ligados a regiões com baixos índices educacionais. Tal padrão espacial se reproduz na distribuição do PIB per capita, utilizado como medida do nível de desenvolvimento das regiões.

Os testes de Indicadores de Associação Espacial Local (LISA) confirmaram a suspeita de existência de clusters com associação positiva entre o capital criativo e capital humano ao desenvolvimento econômico nas microrregiões da metade Sul do Brasil. Tais resultados corroboram os pressupostos trazidos pelas Teorias de Capital Criativo e de Capital Humano em que a participação de trabalhadores criativos e o nível de educação dos indivíduos de uma região influencia seu nível de desenvolvimento econômico. Assim, entende-se que ambas variáveis de emprego criativo e educação dos trabalhadores estão associadas com as diferenças nos níveis de renda das microrregiões.

No entanto, os resultados do capital humano, em comparação ao capital criativo, mostraram-se de maior poder explicativo sendo assim considerada como a melhor variável a explicar o grau de desenvolvimento econômico nas microrregiões brasileiras. Essa evidência reforça os argumentos dos autores críticos à Teoria do Capital Criativo, ao considerar o maior poder explicativo do Índice de educação para o padrão de PIB per capita.

Por fim, apesar do menor poder explicativo encontrado, entende-se que Florida (2011) trouxe uma visão moderna e inovadora à Teoria do Capital Humano, incorporando em sua reflexão características compatíveis com a realidade contemporânea. Estudos futuros podem dar maior atenção a participação dos informais e de atividades que não visam o ganho econômico, assim como investigar as amenidades das microrregiões que se mostraram como atrativas, compreendendo o seu papel na promoção da criatividade e diversidade da população. Entende-se que o presente estudo contribuiu para a identificação de fatores que interferem no desenvolvimento das regiões e que podem auxiliar na elaboração de políticas públicas mais eficientes relacionadas à atração, retenção e desenvolvimento de pessoas.

\section{REFERÊNCIAS}

ALMEIDA, E. Econometria Espacial Aplicada. 1. ed. Campinas: Alínea, 2012. 498p.

ANSELIN, L. Spatial Econometrics: Methods and Models. Santa Barbara: Kluwer Academic Pub, 1999. 284p.

BAUMONT, C. Spatial effects in housing price models: do house prices capitalize urban development policies in the agglomeration Dijon (1999)? Université de Bourgogne: Laboratoire d'économie et de gestion Research Report, p. 1-26, 2004.

BECKER, G. S. Human Capital Revisited. In: BECKER, G. S. Human Capital: a theoretical and empirical analysis with special reference to education. National Bureau of Economic Research, 1994. p. 15-28. 
CARNEIRO, D. R. F. Políticas de incentivo à escola melhoram a proficiência no ensino fundamental? Uma avaliação do prêmio escola nota dez. 2015. 41 f. Dissertação (Mestrado em Economia) - Universidade Federal do Ceará, Fortaleza, 2015.

FAGGIN, A.; McCANN, P. Human Capital and Regional Development, In: CAPELLO, R. e NIJKAMP, P. Handbook of Regional Growth and Development Theories. Edwards Elgar Publishing, 2009. p. 133-151.

FOCHEZATTO, A.; TARTARUGA, I. Atividades econômicas potencialmente inovadoras e desenvolvimento regional no Rio Grande do Sul. Revista Brasileira de Economia de Empresas, Brasília, v. 15, n. 1, p. 85-104, 2015.

FLORIDA, R. A ascensão da classe criativa. Tradução: Ana Luiza Lopes. 1. ed. Porto Alegre: L\&PM, 2011. 456p.

FLORIDA, R. Cities and the Creative Class. City \& Community, v. 2, n. 1, p. 3-19, 2003.

FLORIDA, R. The Economic Geography of Talent. Annals of the Association of American Geographers, Oxford, v. 92, n. 4, p. 743-755, 2002.

FLORIDA, R. The rise of the creative class, revisited: 10th Anniversary Edition. New York: Basic Books, 2012. 483p.

FLORIDA, R.; GATES, G. Technology and tolerance: the importance of diversity to hightechnology growth. In: CLARK, T. N. The City as an Entertainment Machine. Bingley: Emerald Group Publishing Limited, 2003. p. 199-219.

FLORIDA, R.; TINAGLI, I. Europe in the creative age. London: Demos, 2004. 48p.

GLAESER, E. L. Review of Richard Florida's The Rise of Creative Class. Regional Science and Urban Economics. v. 35, p. 593-596, 2005.

HOYMAN, M.; FARICY, C. It Takes a Village: a test of the creative class, social capital, and human capital theories. Urban Affairs Review. v. 44, n. 3, p. 311-333, 2009.

IBGE - Instituto Brasileiro de Geografia e Estatística. Regiões de Influência das Cidades - 2007. Rio de Janeiro: IBGE, 2008.

KERIMOGLU, E.; KARAHASAN, B. C. Location Patterns of Creative Capital and Regional Disparities in Spain. Regional and Sectoral Economics Studies, Euro-American Association of Economic Development Studies, v. 14, n. 1, p. 114-139, 2014.

LANDRY, C. Origens e futuros da cidade criativa. 1. ed. São Paulo: SESI, 2013. 96p.

LIMA, R. C. A.; LIMA, J. P. R. Distribuição do PIB per capita nas microrregiões brasileiras: uma análise exploratória espacial. Planejamento e Políticas Públicas, Brasília, n. 47, p. 306-329, 2016.

LUCAS, R. E. On the mechanics of economic development. Journal of monetary economics. v. 22, n. 1, p. 3-42, 1988.

MANKIW, N. G; ROMER, D.; WEIL, N. D. A contribution to the empirics of economic growth. Quarterly Journal of Economics, 1992. p. 407-437. 
MARKUSEN, A. Urban development and the politics of a creative class: evidence from a study of artists. Environment and Planning, v. 38, n. 10, 1921-1940, 2006.

MELlANDER, C.; FLORIDA, R. The Creative Class or Human Capital? Explaining Regional Development in Sweden. 2006. 39p.

MINCER, J. Investment in human capital and personal income distribution. Journal of Political Economy, v. 66, n. 4, p. 281-302, 1958.

SELTZER, K.; BENTLEY, T. The Creative Age: knowledge and skills for the new economy. London: Demos, 1999. 109p.

SEN, A. K. Desenvolvimento como liberdade. 1. ed. São Paulo: Companhia das letras, 2000. $464 p$.

SIMON, C. J.; NARDINELLI, C. Human capital and the rise of American cities, 1900-1990. Regional Science and Urban Economics. v. 32, n. 1, p. 59-96, 2002.

VIVANT, E. La classe créative existe-t-elle? Discussion des thèses de Richard Florida. Les Annales de la Recherche Urbaine. n. 101, p. 155-161, 2006. 